\title{
High-Dose Fentanyl Patch for Cancer Pain
}

\author{
Sasson Menahem, MD, and Pesach Shvartzman, MD
}

Objective: To describe a successful experience with a high dose (1000 $\mu \mathrm{g} / \mathrm{hr})$ of transdermal fentanyl for cancer pain relief.

Case Report: A 62-year-old man suffering from rectal carcinoma was treated by our home care hospice unit during his last 3.5 months of life. At admission to our home care unit, he suffered mostly from severe anal pain (verbal pain scale of 10/10) due to advanced disease. He was then on $150 \mu \mathrm{g} / \mathrm{hr}$ transdermal fentanyl. Adjuvant therapy with amitriptyline $50 \mathrm{mg} /$ day and dexamethasone $4 \mathrm{mg} /$ day was added, but it did not relieve his pain. The dose of transdermal fentanyl was increased gradually to 1000 $\mu \mathrm{g} / \mathrm{hr}$ with good pain control (verbal pain scale of 1 to $4 / 10$ most of the time). Before his death, he was mentally alert with good pain control.

Conclusions: High doses of transdermal fentanyl $(1000 \mu \mathrm{g} / \mathrm{hr} ; 10$ patches $)$ should be considered for pain relief in cancer patients. (J Am Board Fam Pract 2004;17:388-90.)

During the last decade, fentanyl patch [transdermal therapeutic system (TTS)] has been introduced to the arsenal of opioids for cancer pain control. ${ }^{1,2}$ These patches are a good choice for patients with swallowing difficulties, adherence problems, consciousness changes, and those needing opioid rotation due to side effects. ${ }^{3}$ It has also been reported to cause less constipation compared with other opioids. $^{1,4}$

Fentanyl has been incorporated into a transdermal therapeutic system containing a rate-limiting membrane that provides constant release of the opioid from a reservoir. ${ }^{5}$ Plasma fentanyl concentrations are barely detectable for about 2 hours after patch placement. Eight to 12 hours after patch placement, concentrations approximate those achieved with equivalent intravenous doses of fentanyl. ${ }^{6}$ It is recommended that the patches be changed every 72 hours. $^{7}$ They are available in 4 doses according to the surface area of the patch $(25$, 50, 75, and $100 \mu \mathrm{g} / \mathrm{hr}){ }^{1}$

The upper reported dose in the conversion scale between fentanyl and other strong opioids is up to

Submitted, revised, 20 April 2004.

From the Pain and Palliative Unit, Department of Family Medicine, Sial Research Center for Family Medicine and Primary Care, Ben-Gurion University of the Negev, and Clalit Health Services-South District, Beer-Sheva, Israel. Address correspondence to Dr. Sasson Menahem, Department of Family Medicine, Faculty of Health Sciences, BenGurion University of the Negev, POB 653, Beer-Sheva, 84105, Israel (e-mail: sassonm@bezeqint.net).
$300 \mu \mathrm{g} / \mathrm{hr}$ according to the manufacturer (JanssenCilag, High Wycombe, Bucks, UK). ${ }^{8}$ Although it is well known that while using opioids there is no upper dose limit and "the sky is the limit," this is the first report on good pain control with such a high dose of fentanyl patches in the literature.

\section{Case Report}

A 62-year-old man suffering from rectal carcinoma was treated by our home care hospice unit during his last 3.5 months of life. A year and a half before his admission, a rectal carcinoma was diagnosed and treated by preoperative chemotherapy and radiotherapy, followed by anterior rectal resection. A few months later, a left colostomy was performed because of tumor recurrence. He suffered also from retroperitoneal fibrosis, which caused bilateral hydronephrosis and renal failure. Thereafter, he had bilateral nephrostomy tubes.

On admission to our home care hospice, he suffered from severe anal pain (verbal pain scale, 10/10) on $150 \mu \mathrm{g} / \mathrm{hr}$ fentanyl patches; thus, the dose of fentanyl was immediately increased to 200 $\mu \mathrm{g} /$ day. Adjuvant therapy with $50 \mathrm{mg} /$ day amitriptyline and $4 \mathrm{mg}$ /day dexamethasone was added in the week after admission, with the assumption that there was a neuropathic component to his pain, but it did not relieve his pain. Thereafter, the number of patches was gradually increased. Ten days after admission, the dose was $400 \mu \mathrm{g} / \mathrm{hr}$; after an additional 2 weeks, the dose was increased to $600 \mu \mathrm{g} / \mathrm{hr}$. 


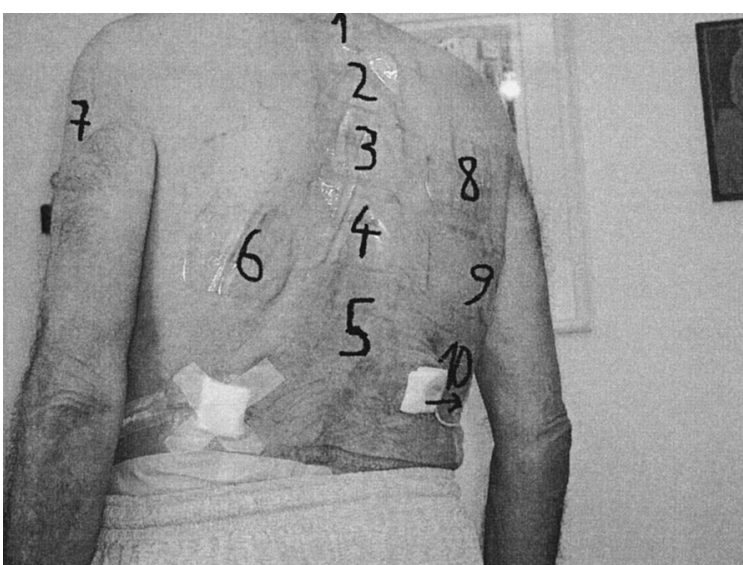

Figure 1. The patient 3 weeks before his death, showing the 10 patches and bilateral nephrostomy tubes.

He also used breakthrough doses of morphine immediate release (MIR) tablets, 1 to 3 times a day, up to $120 \mathrm{mg}$ at a time. Although he was advised to take higher doses of MIR tablets for each dose as the conversion scale required, he reported sufficient pain relief. Once the patient was on $800 \mu \mathrm{g} / \mathrm{hr}$ fentanyl, 2 months after admission, and $120 \mathrm{mg}$ of MIR tablets was not sufficient for pain relief, we converted the breakthrough doses to syrup methadone, $100 \mathrm{mg}$ up to 3 times a day, which provided sufficient pain relief (verbal pain scale, 1 to $4 / 10$ ).

Methadone was used for 3 reasons: (1) for the adjuvant influence on neuropathic pain compared with other opioids (as an $\mathrm{N}$-methyl-D-aspartate receptor antagonist), these receptors are mediators of neuropathic pain; (2) to avoid a large number of pills needed for breakthrough pain; and (3) to convert the large number of patches to a syrup taken 3 times a day.

Unfortunately, the patient did not like the taste of the methadone syrup and stopped using it. Thus, we could not convert the fentanyl patches to methadone syrup. In the 3 weeks before the patient's death, the dose reached $1000 \mu \mathrm{g} / \mathrm{hr}$ fentanyl patches (10 patches). At this dose, the patient was mentally alert, with good pain relief, and was able to walk independently at home with no exacerbation of opioid side effects. The patches were changed by his wife with no problem of finding enough skin area, as shown in Figure 1. There were incidental drops of a single patch from time to time in the higher doses; his wife successfully replaced these patches with no change in pain control (Figure 1).

\section{Discussion}

About $70 \%$ of cancer patients suffer from severe pain in the advanced stages of their illness. ${ }^{9}$ Opioid narcotics are the cornerstone drugs for severe cancer pain treatment with or without adjuvant drugs. ${ }^{10}$ Adjuvant medications are often needed for nonvisceral pain. The main adjuvants are tricyclic antidepressants, local anesthetics, anticonvulsants for neuropathic pain, glucocorticosteroids and nonsteroidal anti-inflammatory drugs for bone pain, glucocorticoids for increased intracranial or nerve pressures, and muscle relaxants for muscle pain. Approximately $85 \%$ of cancer patients will have good pain relief only by medications. ${ }^{11}$ The rest will need adjuvant modalities, such as radiotherapy, chemotherapy, nerve blocks, spinal catheters, cordotomy, and physical or behavioral therapies, for adequate pain relief.

There are basic principles for using opioids for cancer pain. The oral route is preferred. When the patient can no longer use the oral route, the opioids can be switched to transdermal patches, rectal, subcutaneous, or intravenous routes. Titration begins first with short-acting opioids, and when pain control is achieved, the patient is switched to an equally potent dose of a long-acting agent (in this case fentanyl). The key principle is to use an amount of the long-acting agent that is equally potent to the total daily dose of the opioid. Use of extra doses of short-acting opioids to cover breakthrough pain is another principle, with some fraction of the breakthrough doses added the next day to the regularly scheduled dose of extended action narcotic. Using this method of titration allows the doses to be rapidly and safely adjusted upward to match the level of existing pain for the patient. Another key concept is to administer the doses of the medication on a regular schedule to prevent the return of the pain, thereby relieving the patient of the psychological fear of pain. ${ }^{12,13}$

There have been many reports on the efficacy and convenience of fentanyl patches in controlling cancer patients' pain and chronic noncancer pain. ${ }^{1-4,14}$ The early highest dose reports at the beginning of the 1990s were approximately 500$525 \mu \mathrm{g} / \mathrm{hr}$ of fentanyl patches. ${ }^{15,16}$ Radbruch et $\mathrm{al}^{14}$ reported an open prospective survey of 1005 pa- 
tients mostly with chronic cancer pain treated with transdermal fentanyl. The median dose of transdermal fentanyl 4 months after the beginning of treatment was $100 \mu \mathrm{g} / \mathrm{hr}$. The highest dose reported in this study was $900 \mu \mathrm{g} / \mathrm{hr}$ with no details regarding pain relief or side effects. Three of the 1005 patients reported difficulties finding enough skin area for the patches because of the high number of patches. The highest reported dose was used in a woman who suffered from neuropathic pain in her left shoulder and scapula due to a Pancoast tumor of the left lung. She was given transdermal fentanyl in a dose of $3400 \mu \mathrm{g} / \mathrm{hr}$ (ie, 34 patches of $100 \mu \mathrm{g} / \mathrm{hr}$ each). Nevertheless, this huge dose was ineffective in controlling her neuropathic pain with other adjuvant drugs. Only an epidural catheter with infusion of bupivacaine and morphine efficiently controlled her pain. ${ }^{17}$

In the case reported here, the fentanyl dose was equianalgesic to a 3500 - to $4000-\mathrm{mg}$ dose of oral morphine/24 hours. Administering this dose orally would require a large amount of tablets to be taken daily, which makes opioid rotation uncomfortable. The limiting factor for fentanyl patches in high doses is the body surface area. Hairy skin or areas that are not flat are also not suitable for fentanyl patches. In the figure, it can be noted that there is enough surface area for more patches if needed.

High doses of fentanyl patches may be considered in cases of a need for megadoses of opioids to control cancer pain when no parenteral equipment is convenient or available. More studies comparing the convenience to the patient and caregiver and the efficacy and side effects of high doses of fentanyl patches versus high doses of other opioids by oral or parenteral routes can clarify this technique.

\section{References}

1. Muijsers BR, Wagstaff AJ. Transdermal fentanyl-an updated review of its pharmacological properties and therapeutic efficacy in chronic cancer pain control. Drugs 2001;61:2289-307.
2. Cherny N. New strategies in opioid therapy for cancer pain. J Oncol Manag 2000;9:8-15.

3. Skaer TL. Management of pain in the cancer patient. Clin Ther 1993;15:638-49.

4. Allan L, Hays H, Jensen NH, et al. Randomized crossover trail of transdermal fentanyl and sustained release oral morphine for treating chronic non-cancer pain. BMJ 2001;322:1154-8.

5. Sloan PA, Moulin DE, Hays H. A clinical evaluation of the transdermal therapeutic system fentanyl for the treatment of cancer pain. J Pain Symptom Manage 1998;16:102-11.

6. Calis KA, Kohler DR, Corso DM. Transdermally administrated fentanyl for pain management. Clin Pharm 1992;11:22-36.

7. Ahmedzai S. New approaches to pain control in patients with cancer. Eur J Cancer 1997;33 Suppl 6:S8-14.

8. Duragesic (Fentanyl transdermal system) full prescribing information. New Brunswick (NJ): Janssen Pharmaceutica; 2001.

9. Bonica JJ. Treatment of cancer pain: current status and future needs. In: Fields HL, Dubner R, Cervero $\mathrm{F}$, editors. Advances in pain research and therapy. Vol 9. New York (NY): Raven Press; 1985. p. 589616.

10. Moynihan TJ. Use of opioids in the treatment of severe pain in terminally ill patients; dying should not be painful. Mayo Clin Proc 2003;78:1397-579.

11. Vielhaber A, Portenoy RK. Advances in cancer pain management. Hematol Oncol Clin North Am 2002; 16:527-41.

12. Billings JA. Palliative care. BMJ 2000;321:555-8.

13. Cleary JF. Cancer pain management. Cancer Control 2000;7:120-31.

14. Radbruch L, Sabatowski R, Petzke F, BrunschRadbruch A, Grond S, Lehmann KA. Transdermal fentanyl for the management of cancer pain: a survey of 1005 patients. Palliat Med 2001;15:309-21.

15. Lehr VT, Renaud EA. High transdermal fentanyl requirements in a patient with chronic cancer pain. Ann Pharmacother 1993;27:575-8.

16. Simmonds MA, Richenbacher J. Transdermal fentanyl: long-term analgesic studies. J Pain Symptom Manage 1992;3 Suppl:S36-9.

17. Bleeker CP, Bremer RC, Dongelmans DA, van Dongen RTM, Crul BJ. Inefficacy of high-dose transdermal fentanyl in a patient with neuropathic pain: a case report. Eur J Pain 2001;5:325-9. 